\title{
Saberes para a prática docente
}

\author{
Knowledge for teaching practice \\ Conocimiento para la práctica docente
}

\section{Resumo}

Esse texto brotou da necessidade de compreender as diferentes abordagens que fundamentam a docência e o ato de ensinar como parte da realização da educação formal. Assim sendo, o objetivo geral deste estudo é demonstrar as principais abordagens dos saberes docentes e a prática do ensino em sua relação com as correntes pedagógicas. Como objetivos específicos enumeramos: a) apresentar uma abordagem das ideias sobre o ofício de ensinar e dos saberes da docência; b) destacar as teorias formal, prescritiva e normativa do ato de ensinar e c) discutir as principais correntes pedagógicas. Trata-se de uma pesquisa de caráter qualitativo do tipo bibliográfica, bibliométrica e análise de conteúdo e se fundamentou nas contribuições dos seguintes teóricos: Gauthier; Martineau; Desbiens, Malo \& Simard (1997); Gage (2009); Perrenoud, Thuler, De Macedo, Machado \& Allessandrini, (2002). Dentre os resultados percebemos que as diferentes correntes pedagógicas existentes demostram a grande variedade de pensamentos que o docente precisa conhecer para então se apropriar de alguma ou de várias na sua trajetória como docente.

Palavras-chave: Docência; Saberes docentes; Correntes pedagógicas; Ensino.

\begin{abstract}
This text grew out of the need to understand the different approaches that underlie teaching and the act of teaching as part of the realization of formal education. Therefore, the general objective of this study is to demonstrate the main approaches to teaching and teaching practice in relation to pedagogical trends. As specific objectives we enumerate a) to present an approach to the ideas about the teaching profession and the knowledge of teaching; $b$ ) highlight the formal, prescriptive, and normative theories of teaching and c) discuss the main pedagogical trends. It is a qualitative research of the bibliographic, bibliometric and content analysis type and was based on the contributions of the following theorists: Gauthier; Martineau; Desbiens, Malo \& Simard (1997); Gage (2009); Perrenoud, Thuler, De Macedo, Machado \& Allessandrini, (2002). Among the results, we noticed that the different pedagogical currents that exist demonstrate the wide variety of thoughts that the teacher needs to know in order to appropriate some or more in his career as a teacher.
\end{abstract}

Keywords: Teaching practice; Teaching knowledge; Pedagogical currents; Teaching.

\section{Resumen}

Este texto surgió de la necesidad de comprender los diferentes enfoques que subyacen a la enseñanza y el acto de enseñar como parte de la realización de la educación formal. Por lo tanto, el objetivo general de este estudio es demostrar los principales enfoques de la enseñanza y la práctica docente en relación con las tendencias pedagógicas. Como objetivos específicos enumeramos a) presentar un enfoque de las ideas sobre la profesión docente y el conocimiento de la enseñanza; b) resaltar las teorías formales, prescriptivas y normativas de la enseñanza yc) discutir las principales tendencias pedagógicas. Es una investigación cualitativa del tipo de análisis bibliográfico, bibliométrico y de contenido y se basó en las contribuciones de los siguientes teóricos: Gauthier; Martineau Desbiens, Malo y Simard (1997); Gage (2009); Perrenoud, Thuler, De Macedo, Machado y Allessandrini, (2002). Entre los 
resultados, notamos que las diferentes corrientes pedagógicas que existen demuestran la gran variedad de pensamientos que el maestro necesita saber para apropiarse de algunos o más en su carrera como maestro.

Palabras clave: Práctica docente; Enseñanza del conocimiento; Corrientes pedagógicas; Enseñanza.

\section{Introdução}

Este artigo é um conjunto de reflexões sobre a docência fundamentadas nas abordagens empíricas de Bruner, 2001; Dewey, 2008; Gage, 2009; Gauthier, Martineau, Desbiens, Malo e Simard, 1997; Perrenoud, Thuler, De Macedo, Machado e Allessandrini, 2002; Mizukami, 2015; Tardif, 2005; Tardif e Lessard ,2011; Tardif, Lessard e Lahaye, 1991, que surgiram da necessidade de compreender as diferentes ideias sobre a docência e o ensino como parte da realização da educação formal. Assim sendo, o objetivo geral deste estudo é demonstrar as principais abordagens da docência e do ensino em sua relação com as escolas pedagógicas. Os objetivos específicos são: a) apresentar uma abordagem das ideias sobre o ofício de ensinar e dos saberes da docência; b) destacar as teorias formal, prescritiva e normativa do ato de ensinar e c) discutir as principais escolas pedagógicas: escola tradicional, escola nova, escola tecnicista, escola libertadora e Andragogia.

Como metodologia nessa trajetória optamos por uma pesquisa de caráter qualitativo do tipo bibliográfica e bibliométrica que contribuiu para o aprofundamento da reflexão sobre as principais abordagens da docência e do ensino e, concomitantemente, usamos a análise de conteúdo tomando como referência, representativamente, os seguintes teóricos Gauthier; Martineau; Desbiens, Malo et Simard (1997); Gage (2009); Perrenoud, Thuler, De Macedo, Machado et Allessandrini, (2002). No entanto, outros autores como Bruner (2001), Dewey (2008); Mizukami, (2015); Tardif, Lessard et Lahaye (1991); Tardif et Lessard (2011) Tardif (2005), que são abordados no texto com intuito de corroborar com as abordagens levantadas na pesquisa.

O texto está organizado em três momentos. No primeiro momento, com o intuito de apresentar a discussão sobre a docência e o ensino, descrevemos o surgimento da docência, demostrando os saberes docentes de acordo com as reflexões dos pesquisadores (Gauthier; Martineau; Desbiens, Malo \& Simard,1997). No segundo momento abordamos na concepção de Gage (2009) as teorias formal, prescritiva e normativa sobre o ato de ensinar. No terceiro momento, abordamos as escolas pedagógicas que são também denominadas correntes pedagógicas e finalmente nas considerações do trabalho enfatizamos a importância de conhecer o tema, refletir sobre as interpretações sobre a docência e conjeturar sobre a profissionalização da categoria.

\section{Metodologia}

O presente estudo foi desenvolvido por meio de uma pesquisa de caráter qualitativo e quantitativo, pois buscou-se compreender como a realidade social é construída: a pesquisa qualitativa responde a questões muito particulares. Ela se ocupa, nas Ciências Sociais, com um nível de realidade que não pode ser apenas quantificada. Isto é, ela trabalha com o universo dos significados, dos motivos, das aspirações, das crenças, dos valores e das atitudes (Minayo, 2009, p.21). Por meio deste estudo objetivou-se entender como a realidade social, marcada pela educação, influencia na construção social da realidade.

Trata-se de uma pesquisa bibliográfica, já que ela estará fundamentada, essencialmente, na consulta a livros, revistas, dentre outros relacionados. As concepções e/ou taxonomias utilizadas como bases principais para o desenvolvimento deste texto, foram: Gauthier; Martineau; Desbiens, Malo e Simard (1997); Gage (2009); Perrenoud, Thuler, De Macedo, Machado e Allessandrini, (2002). Tais autores foram destacados no trabalho por serem os mais conceituados no âmbito da referida pesquisa e por terem sido mais acessíveis na pesquisa bibliográfica realizada.

A pesquisa bibliográfica e bibliométrica teve como referência o tema saberes docentes, aprendizagem, avaliação do professor e avaliação docente como descritores no período de 2010 a 2020 no portal de periódicos da Coordenação de 
aperfeiçoamento de pessoal de nível superior - CAPES e revisados por pares; o levantamento desenvolve-se no mês de julho de 2020.

\section{Docência}

A docência é um ofício universal que ultrapassou gerações e possui uma história que remonta a Grécia antiga e que influência nossa sociedade contemporânea. A partir da formalização foram-se desenvolvendo teorias relacionadas a educação, ao ensino e à docência.

Nesta perspectiva consideramos as pesquisas desenvolvidas pelos professores pesquisadores (Gauthier et al., 1997) muito pertinentes, pois fazem uma reflexão profunda a respeito dos saberes docentes para o ato de ensinar.

O ato de ensinar nos remete a frase emblemática "conhece-te a ti mesmo" de Sócrates colocada na soleira da entrada do templo do oráculo Delfo. (Gauthier et al., 1997, p.19) Essa frase traz significações sobre a autoavaliação, sobre as fragilidades e as potencialidades do indivíduo. Na perspectiva docente, as fragilidades e as potencialidades das práticas existem e por vezes estão estabelecidas no exercício do magistério e as fragilidades podem ocorrer de serem repetidas sem as devidas reflexões. Os referidos autores acima descrevem em sua pesquisa seis ideias preconcebidas sobre o ofício docente.

A primeira ideia apontada por (Gauthier et al., 1997) é que "basta conhecer o conteúdo" remete o ensino a transmissão de conteúdo para os alunos e estes aprendendo poderão ensiná-lo. Esse pensamento equivocado permeia o ofício docente e desmitificá-lo não é tarefa fácil, mesmo no século XXI. Entretanto, para exercer o magistério sabe-se que o conteúdo é somente uma dimensão do ensino, dessa forma é necessário "planejar, organizar e avaliar". (p.20)

A segunda ideia sobre a docência é que "basta ter talento", o talento é fundamental, quando acompanhado de trabalho e reflexão sobre a prática para reforçar o talento. (Gauthier et al.,1997, p.21, tradução nossa)

A terceira ideia sobre a docência diz que "basta ter bom senso", (p. 21) se nos reportamos para Descartes no Discurso do Método, o bom senso depende de cada pessoa e para Descartes cada indivíduo vai garantir ter o bom ou ainda o melhor senso em comparação ao outro, mas sabemos que não podemos reduzir a prática docente ao uso somente da razão (Souza, 2016).

A quarta ideia é seguir a intuição. Para Gauthier et al. (1997)

A intuição é uma imagem à parte do saber docente, pois se insere numa relação de negação do saber. De fato, seguir sua intuição implica, em última análise, ouvir as "mensagens" de sua consciência, arriscando-se a ir de encontro à sua própria razão. A intuição já foi definida como sendo "uma imagem sem pensamento". Assim quando alguém tem a intuição de realizar um determinado gesto, está respondendo a uma espécie de comando interior, sem passar pela deliberação racional (Gauthier et al., 1997, p. 22, tradução nossa).

Nesta perspectiva seguir a intuição no magistério é agir sem reflexão, sem senso crítico, essa ação contribui para a falta de pensamento crítico das práticas docentes e consequentemente a estagnação.

A quinta ideia sobre docência é que "basta ter experiência", muitos professores afirmam que aprenderam a ensinar na prática, por isso enfatizam a prática em detrimento da teoria. Gauthier et al. (1997) argumenta que o saber vindo da experiência é importante não somente na docência como em qualquer domínio. Entretanto, aprender somente com a prática não pode resumir o saber docente, pois necessita de conhecimentos certificados prévios para lê e interpretar a realidade da sala de aula. (p. 22, tradução nossa)

A sexta ideia de ver o ensino com um olhar míope é querer resumir o saber docente a cultura do profissional. Assim não basta ter cultura para exercer este ofício, mesmo que este seja essencial, este saber não pode ser o único a contribuir no ofício da docência. Atualmente observamos uma maior valorização da cultura dos índios, negros, a cultura das regiões, entre 
outras, entretanto apesar da importância da valorização, a cultura não pode ser o único elemento de contribuição do docente no ensino.

A relação das ideias levantadas pelos pesquisadores Gauthier et al., (1997) nos mostra a identificação do exercício da docência e reforça que o docente não necessita de um saber, mas de vários saberes que irão ajudá-lo no cumprimento do seu ofício. Entendemos que o desafio da profissionalização docente inicialmente não considerava a complexidade do ensino, pois estavam interessados em estudos e pesquisas unilaterais que focavam o aluno em sua aprendizagem e a avaliação professor na opinião do aluno. Entretanto novos elementos estão sendo incorporados, nessa direção, pesquisas sobre o tema saberes docentes de 2010 a 2020 são 3.956 trabalhos indexados no portal de periódicos da Coordenação de aperfeiçoamento de pessoal de nível superior - CAPES; com o tema aprendizagem são 17.236 trabalhos e sobre avaliação do professor 8.143 e avaliação docente 3.075. Este levantamento ocorreu no mês de julho de 2020 e foram considerados somente os trabalhos em periódicos CAPES (2020) revisados por pares. (da pesquisa)

Os resultados e discussões das pesquisas agregaram na formação do docente em exercício, mas também para o docente em formação por meio de melhorias do programa de iniciação à docência (PIBID) criado em 2007 e regulamentado em 2013 e o programa de residência pedagógica instituído pela Coordenação de aperfeiçoamento de pessoal de nível superior CAPES em 2018 e regulamentada em 2019. (Capes, 2010, 2018 \& Capes 2019) Anterior a Gauthier et al., (1997), Tardif, Lessard et Lahaye (1991) já consideravam que vários saberes são mobilizados para apoio do docente para as situações e necessidades diversas durante o magistério, saberes que o docente deverá ter reservado como em um reservatório de saberes. Como conferimos na Tabela 1:

Tabela 1: O reservatório de saberes.

\begin{tabular}{|c|c|c|}
\hline SABERES & O QUE É & CONHECIMENTO \\
\hline $\begin{array}{l}\text { DISCIPLINARES } \\
\text { (A MATÉRIA) }\end{array}$ & $\begin{array}{l}\text { Saber produzido por pesquisadores e cientistas nas disciplinas, é o sabe } \\
\text { que compõe as diversas áreas de conhecimento e está integrado à } \\
\text { universidade como disciplinas, esse saber não é produzido pelo } \\
\text { docente, mas é necessário para o ato de ensinar. }\end{array}$ & $\begin{array}{l}\text { Este saber equivale ao } \\
\text { conhecimento do conteúdo à } \\
\text { ser ensinado. }\end{array}$ \\
\hline $\begin{array}{l}\text { CURRICULARES } \\
\text { (O PROGRAMA) }\end{array}$ & $\begin{array}{l}\text { No saber curricular, a disciplina para fazer parte do currículo passa por } \\
\text { transformações. Dessa forma, ocorre adaptação, inclusão de saberes } \\
\text { que são produzidos pela ciência para serem ensinados no "programa de } \\
\text { ensino" (p. } 30 \text { ) }\end{array}$ & $\begin{array}{l}\text { Este saber equivale ao } \\
\text { conhecimento do programa } \\
\text { de ensino }\end{array}$ \\
\hline $\begin{array}{l}\text { DAS CIÊNCIAS DA } \\
\text { EDUCAÇÃO }\end{array}$ & $\begin{array}{l}\text { O saber específico que não está relacionado com a ação pedagógica, o } \\
\text { saber das ciências da educação demanda noções relativas ao sistema } \\
\text { educativo. }\end{array}$ & $\begin{array}{l}\text { Este saber equivale ao } \\
\text { conhecimento do sistema } \\
\text { educativo }\end{array}$ \\
\hline $\begin{array}{l}\text { DA TRADIÇÃO } \\
\text { PEDAGÓGICA } \\
\text { (O USO) }\end{array}$ & $\begin{array}{l}\text { O saber voltado a tradição pedagógica está relacionado ao que cada } \\
\text { docente traz consigo, ou seja, uma representação da instituição de } \\
\text { ensino, de seus docentes e do modelo de ensino que "serve de molde } \\
\text { para guiar os comportamentos dos professores" (p. 32). }\end{array}$ & $\begin{array}{l}\text { Este saber equivale ao } \\
\text { conhecimento das } \\
\text { representações }\end{array}$ \\
\hline $\begin{array}{l}\text { EXPERIÊNCIAS } \\
\text { (JURISPRUDÊNCIA } \\
\text { PARTICULAR) }\end{array}$ & $\begin{array}{l}\text { O saber experiencial é o saber que se origina da experiência e do } \\
\text { hábito. Essa relação contribui para que o docente apreenda através de } \\
\text { suas experiências. Segundo os autores, os saberes são registrados } \\
\text { "como tal em nosso repertório de saberes. Essa experiência assume } \\
\text { muitas vezes "a forma de uma atividade de rotina" quando não se tem } \\
\text { verificação e discussão cientifica, o docente não sabe justificar porque } \\
\text { tal método deu ou dá mais certo com os alunos no lugar de outro (p. } \\
\text { 33). }\end{array}$ & $\begin{array}{l}\text { Este saber equivale ao } \\
\text { conhecimento das } \\
\text { experiências }\end{array}$ \\
\hline
\end{tabular}




\begin{tabular}{|c|c|c|}
\hline $\begin{array}{l}\text { DA AÇÃO PEDAGÓGICA } \\
\text { (O REPERTÓRIO DE } \\
\text { CONHECIMENTOS DO } \\
\text { ENSINO OU A } \\
\text { JURISPRUDÊNCIA } \\
\text { PÚBLICA VALIDADA }\end{array}$ & $\begin{array}{l}\text { O saber da ação pedagógica é o saber experiencial que se tornou } \\
\text { público, ou seja, saiu dos limites do privado, do achismo, para ser } \\
\text { verificado cientificamente através de pesquisas aplicadas no âmbito da } \\
\text { sala de aula. Dessa forma o discurso dos docentes pode ser comparado, } \\
\text { avaliado, discutido e julgado a fim de "estabelecer regras de ação que } \\
\text { serão conhecidas e apreendidas por outros professores" (p. 33). }\end{array}$ & $\begin{array}{l}\text { Este saber equivale ao } \\
\text { conhecimento das } \\
\text { experiências com verificação } \\
\text { cientifica. }\end{array}$ \\
\hline
\end{tabular}

Fonte: Adaptado (Gauthier et al., 1997, pp. 29-33, tradução nossa).

Como se pode ver, a partir da tabela há definições claras do que vem a ser conhecimento, saberes, etc. Os autores argumentam sobre a importância de se legitimar o saber da ação pedagógica para compartilhar os resultados com os outros docentes.

Os saberes da ação pedagógica legitimados pelas pesquisas são atualmente o tipo de saber menos desenvolvido no reservatório de saberes do professor, e também, paradoxalmente, o mais necessário à profissionalização do ensino. Não poderá haver profissionalização do ensino enquanto esse tipo de saber não for mais explicitado, visto que os saberes da ação pedagógica constituem um dos fundamentos da identidade profissional do professor. De fato, na ausência de um saber da ação pedagógica válido, o professor, para fundamentar seus gestos, continuará recorrendo à experiência, à tradição, ao bom senso, em suma continuará usando saberes que não somente podem comportar limitações importantes, mas também não o distinguem em nada, ou quase nada, do cidadão comum (p. 34, tradução nossa).

O que os autores pretendem com este discurso é esclarecer ao docente e a quem interessar que este ofício necessita realmente de conhecimentos, que o profissional faz uso de acordo com suas necessidades. Ressaltamos também que a partir desse princípio, não temos um docente pronto, mas um docente em evolução, em aprendizado, em processo constante de significação e ressignificação dos conhecimentos, dos seus modelos sobre o comportamento humano, sendo esse acúmulo seu reservatório no exercício da docência necessário aos novos contextos que o docente se encontra e que são cada vez mais desafiadores para o ensino presencial, ensino híbrido, ensino a distância e ensino remoto.

\section{Ensino}

Gage (2009) declara que as teorias de ensino podem ser classificadas em três categorias: teoria formal (teoria filosófica) de ensino; teoria descritiva de ensino e teoria normativa de ensino.

A teoria formal de ensino ou teoria filosófica do ensino se baseia na lógica, na metafísica, na epistemologia e nas proposições. A teoria formal ou teoria formal de ensino reflete as práticas sociais atuais.

A teoria Maiêutica iniciada por Sócrates, por exemplo, que faz parte da teoria formal concebe o processo de ensino fundamentado nas técnicas de questionamento do conhecimento, ou seja, o professor seria uma espécie de parteira que traz seu conhecimento ao nível consciente do discente para que este nasça. O foco desta teoria é a auto realização. Para esse intento, o método socrático é elemento essencial para esta teoria, que se a baseia no autoconhecimento e nos questionamentos sobre as verdades ditas absolutas. O questionar as ideias impostas levam os discentes a obterem suas próprias conclusões e formarem suas opiniões e seus conhecimentos. Sendo assim o docente não seria aquele que dá aula, que dá conteúdo, mas aquele que leva o discente ao questionamento e a fazer suas próprias perguntas e obter suas próprias respostas através da pesquisa. (Souza, 2016)

Na teoria formal, Gage (2009) observam que a hereditariedade desempenha um papel importante no processo de ensino através da teoria da comunicação do Ensino. Esta teoria de ensino é baseada nas premissas que o professor possui todas as informações sobre o conhecimento que o aluno não possui e que necessita. Acredita-se que o discente está em estado limpo 
e a forma mais adequada para o aluno se apropriar desse conhecimento é através do professor que apresenta, explica, demonstra e executa na sala de aula por meio da comunicação.

Outra teoria formal levantada por Gage (2009) é a teoria de moldagem de ensinar, no qual John Dewey (1859-1952) é o defensor. O pressuposto básico sobre a natureza humana que esta teoria leva em consideração é que a personalidade humana é formada e moldada pelo seu ambiente dentro de um dualismo (racionalista e empirista). Dentro dessa perspectiva de interrelação, Dewey (2008) acredita que a experiência que molda o indivíduo ocorre quando um agir de um corpo exerce uma reação sobre outro corpo.

A principal hipótese da teoria do inquérito mútuo, outra teoria abordada por Dewey (2008), considera o conhecimento levantado nas escolas e fora das escolas para a resolução de problemas. Esta teoria do ensino formal é claramente aplicável à investigação e a arte. Esta teoria pressupõe que cada indivíduo tem a capacidade de descobrir novos conhecimentos com o inquérito mútuo. Isso implica que o docente tem um modelo em sua mente para usar em situações específicas.

Gage (2009) acrescenta ainda que a teoria descritiva é baseada em proposições e observações. Esta teoria tem como exemplo a teoria de instrução que consiste em um conjunto de proposições que indicam a relação entre o resultado da educação e as condições de exposição às variáveis que o aluno está exposto. A Teoria do desenvolvimento cognitivo da Instrução teve como defensor Bruner (1915-2016), pois esta Teoria propõe regras, por isso é considerada prescritiva de conhecimento, habilidades e fornece técnicas que avaliam os resultados da aprendizagem. Ela é também considerada normativa na medida em que estabelece metas a serem alcançadas. A teoria de instrução deve se preocupar com a aprendizagem e o desenvolvimento, pois estes devem ser equivalentes com as teorias de aprendizagem e de desenvolvimento.

Bruner (2001) relata alguns passos empíricos necessários antes que a teoria possa prescrever a prática. Em seguida especificou quatro características que uma teoria de instrução deve envolver são elas; a Predisposição para aprender; a Estrutura de conhecimento; a Sequência de instrução e Reforço.

A Predisposição para aprender se refere a teoria de instrução que deve se preocupar com as experiências e contexto que tenderão a tornar a criança disposta e capaz de aprender quando entra na escola.

A Estrutura do conhecimento é a teoria de instrução que deve especificar as maneiras em que o corpo do conhecimento deve ser estruturado de forma que possa ser mais facilmente compreendido pelo aluno.

A Sequência de instrução refere-se à teoria de instrução que deve especificar as sequências mais eficazes para apresentar o material.

O reforço é uma teoria de instrução que deve especificar a natureza e o ritmo das recompensas, passando de recompensas extrínsecas de um intrínseco.

Ressaltamos que é necessário considerar as diferenças existentes entre indivíduos e considerar a idade, a estrutura de conhecimento com o tema a ser ensinado, a flexibilidade de sequenciamento, a taxa de aprendizagem, os interesses e assim por diante, dessa forma qualquer assunto pode ser ensinado para qualquer estudante em qualquer fase de desenvolvimento, as escolhas feitas pelo docente é que vão fazer a diferença na sala de aula.

Além da teoria prescritiva abordada por Gage (1984), este autor aborda também em seu trabalho a teoria normativa que foi formulada através da experiência em situações controladas, portanto, esta teoria tem menos capacidade de generalização nas instituições educacionais, pois nessa perspectiva o ensino pode proceder com base em diferentes famílias de teoria da aprendizagem (teorias filosóficas de aprendizagem que incluem a disciplina mental, o desdobramento e a aprovação; as teorias psicológicas de aprendizagem que inclui a teoria do S-R, estímulo, resposta e a teoria do reforço e Discernimento).

Gage (2009) observa ainda que a atividade do professor é produto de condições sociais. Dessa forma o comportamento bom ou ruim do professor é julgado com referência ao sistema de valores de uma cultura particular e de seus objetivos. Assim como Gage, (2009) Tardif (2005) também vai considerar o trabalho docente como uma prática social pela 
integração dos saberes e das experiências curriculares e disciplinares vivenciadas no cotidiano e construídos a partir da socialização com outros docentes, essa socialização para Gage (2009) era reconhecida como a teoria psicológica de ensinar, onde se percebe a existência de uma relação contratual que se estabelece entre o docente e seus discentes. Esta relação contratual era composta de certas atividades a serem executadas pelo professor tais como: análise da tarefa docente, determinar as metas de aprendizagem, identificar comportamentos de entrada e uma estratégia de ensino que são formuladas pelo o professor de acordo com suas próprias experiências e insight.

Darling-Hammond e Sclan (1996) Hagraves, (1994) em Tardif e Lessard (2011) percebem que a evolução do ensino é notada em diversos países, inclusive no Brasil, pelo controle da atividade docente, dentro de um modelo prescritivo, onde se prescrevem as tarefas, o tempo, o currículo com o intuito de melhorar o resultado discente.

Com o intuito de direcionar diferentemente esse controle, que este não fosse percebido somente na visão do discente, diferentes pesquisas sobre o ensino e a sua utilização nos programas de formação docente foram feitos não somente tendo como base o discurso do discente, mas levando em consideração o que era feito dentro da sala de aula. A partir dos resultados levantados sobre o repertório de saberes, alguns pesquisadores procuraram mostrar a atividade docente seguindo um modelo de ensino que está associado ao que se deseja como rendimento e atitude do discente (Gauthier, Martineau, Desbiens, Malo \& Simard,1997)

Mesmo se conseguíssemos, através da pesquisa, identificar as dezenas e dezenas de correlações que colocam em evidencia comportamentos do professor e efeitos positivos sobre os alunos, ainda assim não seria possível, em virtude das dimensões contraditórias presentes simultaneamente no contexto da sala de aula, que o professor pudesse "aplicar", com toda a calma e mecanicamente, os resultados das pesquisas ao seu contexto específico (Gauthier Martineau, Desbiens, Malo \& Simard,1997, p. 120, tradução nossa).

O que os pesquisadores dizem é que os comportamentos de sucesso aplicados pelos professores não garantem o mesmo resultado em outro contexto, outra sala de aula, com outros alunos. Dessa forma os levantamentos feitos não podem ditar como o docente deve agir, mas norteá-lo. Nesse sentido, o pesquisador estaria faltando seriamente com as suas responsabilidades éticas se não indicasse aos professores as limitações de seu próprio trabalho, ciente desses entraves (Gauthier, Martineau, Desbiens, Malo \& Simard,1997).

Apoiando-se nesses autores verificamos inúmeras pesquisas que afirmam que o docente pode ser melhor no exercício do seu magistério. Dias e Porto (2013) pontuam sobre a identidade do professor universitário e a expectativa criada em torno deste profissional, no que diz respeito ao seu desenvolvimento para o trabalho. Entretanto esse interesse no desenvolvimento docente vem envolto da complexidade da função e da falta de políticas públicas que vislumbre a formação no contexto do ensino superior revelando os princípios pertinentes "a realidade na qual vão atuar" e os desafios da formação inicial e entendem que "o fazer pedagógico deve se fundamentar-se na investigação e na reflexão sobre a ação pedagógica". (p.59, tradução nossa).

\section{Correntes Pedagógicas}

Dentro da especificidade da profissão do docente Perrenoud, Thuler, De Macedo, Machado et Allessandrini (2002) revelam que o professor é "antes de tudo um profissional da articulação do processo ensino-aprendizagem em uma determinada situação, um profissional da interação das significações partilhadas". (p.26) Assim nesse processo intencional, onde a comunicação verbal flui com diálogos e questionamentos é que a prática do ensino acontece. Sendo assim, os autores averbam que: 
Ensinar é fazer aprender e, sem a sua finalidade de aprendizagem, o ensino não existe. Porém, este "fazer aprender" se dá pela comunicação e pela aplicação; o professor é um profissional da aprendizagem, da gestão de condições de aprendizagem e da regulação interativa em sala de aula (Perrenoud, Thuler, De Macedo, Machado \& Allessandrini, 2002, p. 26, tradução nossa).

Para que os argumentos (Perrenoud, Thuler, De Macedo, Machado \& Allessandrini (2002) fizessem sentido, constatamos que as correntes pedagógicas evoluíram ao longo dos anos, assim, cada corrente pedagógica significou para educação um avanço, pois existiam características próprias e princípios que as identificam e diferenciam-nas uma da outra. No modelo de educação tradicional, da corrente tradicionalista, é um dos modelos mais conhecidos e antigos. Este modelo centra o aprendizado do aluno no professor, no programa de ensino, nos fatores externos. Sendo assim, o aluno não assume a responsabilidade do seu aprendizado.

A pedagogia Nova surge de forma democrática com enfoque nas particularidades do discente e o colocando no centro do aprendizado. Dessa forma, contradiz os argumentos da pedagogia Tradicional.

A corrente pedagógica tecnicista surge na ideia de entrelaçar ensino e mercado de trabalho, ou seja, uma formação do discente voltada para a produtividade, racionalidade e eficiência, quesitos próprios da revolução industrial (1760 - 1840) e de pensadores como Taylor (1856-1915) que contribuíram para esse evento.

A corrente libertadora é reconhecida facilmente por seus precursores, dentre eles, destacamos Paulo Freire. Além de estabelecer características semelhantes com a pedagogia nova, onde o centro é o discente focaliza-se nas classes sociais, no ensino-aprendizagem de adultos, na busca de uma conscientização social através do conhecimento escolar.

A Andragogia, por sua vez, tem como princípio a compreensão do adulto respeitando sua bagagem experiencial adquirida. Mesmo que seu aprendizado seja orientado, é o adulto que determina o que aprender, pois conhece suas necessidades e sua motivação esta pautada no crescimento intelectual (Mizukami 1986, Bomfin 1998).

A abordagem utilizada na Andragogia se assemelha a utilizada por Ausubel (1963) na Aprendizagem significativa. Percebemos que as duas abordagens partem do princípio de que o indivíduo possui experiências que precisam ser conectadas com as teorias para que ocorra o aprendizado. Sendo assim, o docente é este mediador capaz de perceber e relacionar as experiências do aprendiz com o objetivo do aprendizado.

\section{Considerações Finais}

As questões abordadas neste artigo percorrem a historicidade carregadas de mudanças intensas, algumas rápidas e outras demoradas que inquietam pesquisadores e os instigam para o aprofundamento do tema e a proposição de reflexões, reformulações no assunto como percebido pelo número de publicações sobre o tema na plataforma de periódicos da Capes e comentadas no texto.

No que diz respeito aos nossos objetivos foram alcançados. Ao confrontar nossos objetivos específicos consideramos que ao apresentar uma abordagem das ideias sobre o ofício de ensinar e dos saberes da docência os saberes levantados por Gauthier, Desbiens, Malo; Martineau, e Simard, (1997). Na seguinte nomenclatura: saber da formação profissional, saber disciplinar, saber curricular e saber experiencial permite-nos perceber as necessidades de aprendizado do docente e direcionar o trabalho para o conhecimento que o mesmo tem que ter ou desenvolver sobre sua matéria, sua disciplina, sobre o programa, no qual faz parte, assim que saber sobre as ciências da educação para então através de sua experiência obter um saber prático na relação cotidiana com os discentes.

Ao destacar as teorias formal, prescritiva e normativa do ato de ensinar. A teoria formal conduziria o discente ao autoconhecimento, a curiosidade, a busca pela informação, entretanto a teoria prescritiva possui uma tradição em propor 
regras, por isso é considerada prescritiva de conhecimento, habilidades e fornece técnicas que avaliam os resultados da aprendizagem, essa teoria tem influência ainda atualmente.

Ao discutir as principais escolas pedagógicas: escola tradicional, escola nova, escola tecnicista, escola libertadora e Andragogia, observa-se que as diferentes correntes pedagógicas existentes demostram a grande variedade de pensamentos, no qual o docente precisa conhecer para então se apropriar de alguma ou de várias abordagens na sua trajetória como docente.

Consideramos que várias etapas da história educativa e o número de pesquisas e abordagens desenvolvidas sobre o ensino e à docência resultaram em dizer que existe saberes diversos para que os docentes aprendam e ensinem. Assim, não podemos pensar no discente sem considerar os saberes do docente, pois suas ações contribuem para a eficácia do aprendizado. Nesse sentido, pensar na aprendizagem significativa e na profissionalização docente é identificar conhecimentos com significado que podem ser adquiridos ao longo da trajetória de formação e atuação que permite o docente apoiar-se e refletir sobre o ato de ensinar.

A contribuição desse trabalho foi refletir sobre as principais abordagens da docência e do ensino em sua relação com as escolas pedagógicas. Após a exposição, queremos ressaltar que o docente está em constante aprendizado para a docência e para o ensino acompanhada de significações e ressignificações dos conhecimentos. Como sugestão para um trabalho futuro está em elencar o saber docente com a inovação, tema que tem se destacado entre os docentes.

\section{Referências}

Ausubel, D. P. (1963). The psychology of meaningful verbal learning. Grune \& Stratton. (Autores. A informação está incompleta e portanto, incorreta: em que cidade foi publicado este livro?)

Bonfim, D. (1998). Pedagogia no Treinamento, correntes pedagógicas no treinamento empresarial: Qualitymark.

Bruner, J. (2001). A cultura da educação: Artmed.

CAPES. (2010). Portaria $N^{o} 72$ (09 Abril de 2010). Coordenação de aperfeiçoamento de pessoal de nível superior- CAPES https://capes.gov.br/images/stories/download/legislacao/Portaria72_Pibid_090410.pdf

CAPES. (2018). Portaria Gabinete $N^{o} 38$ (28 fevereiro de 2018). Coordenação de aperfeiçoamento de pessoal de nível superior- CAPES. https://capes.gov.br/images/stories/download/legislacao/28022018-Portaria_n_38-Institui_RP.pdf

CAPES. (2018). Portaria CAPES $N^{o} 175$ (7 agosto de 2018). Coordenação de aperfeiçoamento de pessoal de nível superior- CAPES. https://capes.gov.br/images/stories/download/legislacao/09082018-Portaria_175_Altera_Portaria_45_de_2018.pdf Acesso em 18.03.2020.

CAPES. (2019). Portaria Gabinete $N^{o} 259$ (17 dezembro de 2019). Coordenação de aperfeiçoamento de pessoal de nível superior- CAPES. https://www.capes.gov.br/images/novo_portal/documentos/regulamento/19122019_Portaria_259_Regulamento.pdf

Dewey, J. (2008) O desenvolvimento do Pragmatismo Americano. Cognitio-estudos: Revista Eletrônica de Filosofia, 5(2), 119-32: PUC-SP.

Dias, A. M. I., \& Porto, B. S. (2013) Desenvolvimento da Docência em Nível Superior: de situações vivenciadas na prática à formação de rede de saberes. In: Veiga, I. P.A; Dávila, C. M. (Org.). Profissão docente na educação superior. (1a ed.): Editora CRV, 2013, 1, 1-168.

Gage, N. L. (2009) A Conception of the Process of Teaching. In: A Conception of Teaching. Springer, Boston, MA. https://doi.org/10.1007/978-0387-09446-5_4

Gauthier, C., Desbiens, J.-F., Malo, A., Martineau, S., \& Simard, D. (1997). Pour une théorie de la pédagogie. Recherches contemporaines sur le savoir des enseignants. Saint-Nicolas: Les Presses de l'Université Laval.

Mizukami, M. G. N. (1986) Ensino: as abordagens do processo. São em:https://edisciplinas.usp.br/pluginfile.php/1285594/mod_resource/content/0/ensino_as\%20abordagens\%20do\%20processo.pdf. professores e o desafio da avaliação: Artmed Editora, 2002.

Souza, A. M. C. (2016) Avaliação docente em estágio probatório: Estudo das ações educacionais do programa CASA/UFC-comunidade de Cooperação e aprendizagem significativa. 173 f. Tese (Doutorado em Educação Brasileira) - Universidade Federal do Ceara, Fortaleza. http://www.repositorio.ufc.br/handle/riufc/21833.

Tardif, M. (2005). Saberes docentes e formação profissional: Vozes, 2005.

Tardif, M., \& Lessard, C. (2011) O trabalho docente: elementos para uma teoria da docência como profissão de interações humanas. (6 ${ }^{\mathrm{a}}$ Ed.): Vozes, 2011.

Tardif, M., Lessard, C., \& Lahaye, L. (1991) Os Professores face ao Saber: esboço de uma problemática do saber docente. In: Teoria e Educação. 1991 , v. 04. 